\title{
THE SHIP OF OPPORTUNITY PROGRAM
}

\author{
G. Goni $^{(1)}$, D. Roemmich ${ }^{(2)}$, R. Molinari ${ }^{(3)}$, G. Meyers( ${ }^{(4)}$, C. Sun $^{(5)}$, T. Boyer ${ }^{(5)}$, M. Baringer $^{(1)}$, V. Gouretski( ${ }^{(6)}$, \\ P. DiNezio ${ }^{(3)}$, F. Reseghetti ${ }^{(7)}$, G. Vissa ${ }^{(8)}$, S. Swart ${ }^{(9)}$, R. Keeley ${ }^{(10)}$, S. Garzoli ${ }^{(1)}$,T. Rossby ${ }^{(11)}$, C. Maes $^{(12)}$, \\ G. Reverdin ${ }^{(13)}$ \\ (1) National Oceanic and Atmospheric Administration, Atlantic Oceanographic and Meteorological Laboratory, \\ 4301 Rickenbacker Causeway, Miami, FL 33149, USA, Email: Gustavo.Goni@noaa.gov, \\ Molly.Baringer@noaa.gov, Silvia.Garzoli@noaa.gov \\ (2) University of California in San Diego, Scripps Institution of Oceanography, 9500 Gilman Drive, \\ San Diego, La Jolla, CA 92093 USA, Email: droemmich@ucsd.edu \\ (3) University of Miami, Cooperative Institute for Marine and Atmospheric Studies, 4600 Rickenbacker Causeway, \\ Miami, FL 33149 USA, Email: Bob.Molinari@noaa.gov,Pedro.DiNezio@noaa.gov \\ (4) University of Tasmania, Private Bag 76, Hobart TAS, 7001, Australia, Email: Gary.Meyers@imos.org.au \\ ${ }^{(5)}$ National Oceanographic and Meteorological Laboratory, National Oceanographic Data Center, SSMC3, 4th Floor, \\ 1315 East-West Highway, Silver Spring, MD 20910-3282 USA, \\ Email: Charles.Sun@noaa.gov,boyer@nodc.noaa.gov \\ (6) University of Hamburg, Hamburg, Bundesstr. 53, 20146 Hamburg, Germany, \\ Email: viktor.gouretski@zmaw.de \\ (7) ENEA (Energy and Sustainable Economic Development), Centro Ricerche Ambiente Marino, \\ P.O. Box 224, Località Pozzuolo, Forte, Santa Teresa, I-19030 Lerici, La Spezia Italy, \\ Email: franco.reseghetti@santateresa.enea.it \\ ${ }^{(8)}$ National Institute of Oceanography, Dona Paula - 403 004, Goa, India, Email: vvgkxbt@yahoo.com \\ ${ }^{(9)}$ University of Cape Town, Oceanography Department, Private Bag X3, Rondebosch, Cape Town, \\ South Africa 7701, Email: sswart@ocean.uct.ac.za \\ ${ }^{(10)}$ Integrated Science Data Management, 12th Fl 200 Kent St. Ottawa, ON. Canada. K1A 0E6, \\ Email: KeeleyR@dfo-mpo-gc.ca \\ (11) University of Rhode Island, Graduate School of Oceanography, South Ferry Rd., Narragansett, \\ RIO2882 USA, Email: trossby@gso.uri.edu \\ (12) Institut de Recherche pour le Développement/Laboratoire d'Études en Géophysique et Océanographie Spatiales, \\ B.P.A5-98848 - Noumea Cedex-New Calédonie,Email: christophe.maes@noumea.ird.nc \\ ${ }^{(13)}$ LOCEAN (Laboratoire d'Océanographie et du Climat: Expérimentations et Approches Numériques, \\ University of Paris VI, 4, place Jussieu 75252 Paris Cedex 05, France, \\ Email: Gilles.Reverdin@lodyc.jussieu.fr
}

\section{ABSTRACT}

The Ship Of Opportunity Program (SOOP) is an international World Meteorological Organization (WMO)-Intergovernmental Oceanographic Commission (IOC) program that addresses both scientific and operational goals to contribute to building a sustained ocean observing system. The SOOP main mission is the collection of upper ocean temperature profiles using eXpendable BathyThermographs (XBTs), mostly from volunteer vessels. The XBT deployments are designated by their spatial and temporal sampling goals or modes of deployment (Low Density, Frequently Repeated, and High Density) and sample along well-observed transects, on either large or small spatial scales, or at special locations such as boundary currents and chokepoints, all of which are complementary to the Argo global broad scale array. A multi-national review of the global upper ocean thermal networks carried out in 1999 [1] and presented at the OceanObs'99 conference recommended evolving from broad-scale
\end{abstract}

XBT sampling to increased spatial and temporal transect-based sampling anticipating the implementation of the Argo float network and continued satellite altimetry observations. The objective of the present manuscript is to review the present status of networks against the objectives set during OceanObs'99, to present key scientific contributions of XBT observations, and to offer new perspectives for the future of the XBT network. The commercial shipping industry has changed in the past decade, toward fewer routes and more frequent changes of ships and routing impacting the temporal continuity of some XBT transects. In spite of these changes, many routes now have, in addition to XBT sampling, measurements from ThermoSalinoGraphs (TSGs), eXpendable Conductivity Temperature and Depth (XCTD), partial pressure of $\mathrm{CO}_{2}$, Acoustic Doppler Current Profiler (ADCP), Continuous Plankton Recorders (CPR), marine meteorology, fluorescence, and radiometer sensors. In addition, recent studies of the XBT fall rate are being evaluated 
with the goal of optimizing the XBT historical record for climate research applications. The ongoing value of the Ship Of Opportunity networks is viewed through their extended time-series and their integrative relationships with other elements of the ocean observing system including, for example, profiling floats, satellite altimetry, and air-sea flux measurements. Improved capabilities in ocean data assimilation modeling and expansion to support large scale multidisciplinary research will further enhance value in the future.

\section{THE SHIP OF OPPORTUNITY PROGRAM}

The Ship Of Opportunity Program (SOOP) is an effort by the international community, and addresses both scientific and operational goals for building a sustained ocean observing system. Subsurface data, mostly from XBTs, collected from ships of the SOOP are used to initialize the operational seasonal-to-interannual (SI) climate forecasts and have been shown to be necessary for successful SI predictions. Other key uses of these data are to increase understanding of the dynamics of the SI and decadal time scale variability, to perform model validation studies, and to investigate meridional heat advection at the basin scale. The Ship Of Opportunity Program Implementation Panel (SOOPIP) is one of the three components of the World Meteorological Organization (WMO)Intergovernmental Oceanographic Commission (IOC) Ship of Observations Team (SOT), with the other two being the Voluntary Observing Ship (VOS) and the Automated Shipboard Aerological (ASAP) Programmes. SOOPIP has as a primary objective to fulfill the XBT upper ocean data requirements established by the international scientific and operational communities. The annual assessment of transect sampling is undertaken by the Joint WMOIOC Technical Commission for Oceanography and Marine Meteorology (JCOMMOPS) on behalf of SOOPIP. While SOOPIP deals with ocean observations [2], the VOS (Volunteer Observing System) Programme deals with meteorological observations [3]. Besides carrying out the deployment of XBTs, many ships of the SOOP are used as a platform for the deployment or installation of other scientific equipments, such as XCTDs, ADCPs, CPRs, TSGs, etc.

XBTs are widely used to observe the vertical thermal structure of the upper ocean and constitute a large fraction of the archived ocean thermal data during the $70 \mathrm{~s}, 80 \mathrm{~s}$ and $90 \mathrm{~s}$. In the ocean, the typical maximum sampling depth is to $760 \mathrm{~m}$. Prior to the OceanObs'99 meeting, a white paper [1] was written to examine the status of XBT observations and to provide recommendations on how to proceed with XBT observations and analyses after implementation of the
Argo program. Until the advent of the Argo array, XBTs constituted $50 \%$ of the global ocean thermal observations, providing sampling initially during regional research cruises and recently during research cruises and along major shipping lines. While the Argo array now provides temperature profile observations with a global distribution [4], XBT observations represent approximately $25 \%$ of current temperature profile observations and are used to monitor boundary currents and are the sole practical system for monitoring transports across fixed transects

OceanObs'99 made recommendations on three modes of deployment: High Density (HD), Frequently Repeated (FR), and Low Density (LD). Details of the goals of each mode and of specific transects are provided by [1]. The XBT network is shown in Fig. 1. The sampling requirements for these three modes of deployment are:

- Low Density: 12 transects per year, 4 XBT deployments per day, targeted at detecting the large-scale, low frequency modes of ocean variability.

- Frequently Repeated: 12-18 transects per year, 6 XBT deployments per day (every 100-150 km), aimed at obtaining high spatial resolution observations in consecutive realizations, in regions where temporal variability is strong and resolvable with order 20-day sampling.

- High Density: 4 transects per year, 1 XBT deployment every approximately $25 \mathrm{~km}$ (35 XBT deployments per day with a ship speed of 20kts), aimed at obtaining high spatial resolution in one single realization to resolve the spatial structure of mesoscale eddies, fronts, and boundary currents.

OceanObs'99 recommended the slow phase out of the LD mode if Argo profiling floats together with satellite altimetry data could provide the same type of information. The current XBT transects differ somewhat from the OceanObs'99 recommendations. Therefore, several questions remain to be addressed: 1) Whether the present sampling, particularly differences from the OceanObs'99 recommendations, satisfies the needs of the scientific and operational communities, 2) An assessment of the impact on science and operations because of these differences, and 3) How these issues will be addressed.

The following are the XBT recommendations from OceanObs' 99 and their current status:

\subsection{Status of OceanObs'99 Recommendations}

- Recommendation: Begin a phased reduction in LD sampling and an enhanced effort in FR and HD sampling. Status: LD network has been reduced, 
HD network has been enhanced and FR transects remain essentially constant.

- Recommendation: Base the phased reduction in LD sampling on the implementation of Argo and have sufficient overlap to ensure that there are no systematic differences between XBT and float sampling. Status: Although some LD transects have been discontinued before adequate analyses have been performed, there are several ongoing studies addressing this issue. LD transects that have been occupied for $40+$ years are being reviewed to determine if they provide information on decadal variability in temperature characteristics of the subtropical and subpolar gyres. For example, AX10 (Fig.1) shows decadal meridional migrations of the Gulf Stream (GS) correlated with the North Atlantic Oscillation (NAO), GS transport and size of the southern recirculation gyre [5]. AX03, where the GS joins the North Atlantic Current (NAC) shows decadal variability correlated with that at AX10. AX01 and AX02 cross currents that transport waters into and out of the Nordic seas and Arctic Ocean, crucial components of the MOC. These two transects are no longer occupied regularly and, until the Argo array and satellite altimetry show that they can provide similar results; it is recommended that data collection be restarted.

- Recommendation: Build the FR and HD network on existing transects. Status: Currently underway.

- Recommendation: Data are to be distributed within 12 hours, with minimal intervention. Status: After consultation with operational groups time limit was changed and implemented at 24 hours using automatic quality control tests.

- Recommendation: Perform delayed mode quality control (QC) with improved QC tests. Status: Initially accomplished at three centers (the National Oceanic and Atmospheric Administration Atlantic Oceanographic and Meteorological Laboratory, Australian Commonwealth Scientific and Industrial Research Organisation, and Scripps Institution of Oceanography) under auspices of the Global Temperature-Salinity Profile Program (GTSPP). GTSPP is hosted at the U.S. National Oceanographic Data Center and performs the following tasks: (1) serves as the long term archival center of the XBT network data, and (2) performs the delayed-mode QC tests originally done by the three science centers, but now performed using the Integrated Global Ocean Services System (IGOSS) flags.

- Recommendation: Implement improved communications allowing for full depth resolution transmission. Status: Partially accomplished. It is currently unclear whether the operational community needs full depth resolution profiles in real-time and this recommendation should be evaluated.

- Recommendation: Implement a system of data tagging that will provide a unique identity to each profile. Status: Partially implemented by all centers.

- Recommendation: Implement a system of data quality accreditation in order to better identify data originators if modification of data is needed. Status: Not yet implemented. This implementation will start taking place after the transmission format changes to the Binary Universal Form for the Representation of data (BUFR) in 2011.

- Recommendation: Develop a definitive ocean thermal database. Status: GTSPP was initiated to manage ocean profile data. The program was founded on the principle of the value of a continuously managed database so that at any time a user may have the most up-to-date, highest resolution, highest quality data available. To achieve this, GTSPP instituted standards for data quality, data structures, and project reporting procedures. GTSPP in collaboration with the SOOP is testing the use of unique data identifiers as a way to more effectively identify and hence control data duplication. GTSPP has also initiated support for the Joint World Meteorological Organization (WMO) - Intergovernmental Oceanographic Commission (IOC) Technical Commission for Oceanography and Marine Meteorology (JCOMM) quarterly reports providing information on temperature and salinity profiles. GTSPP has built an international partnership that has served as a model for managing other kinds of data. However, the production of a high quality, global, historical, XBT data set remains to be achieved for reasons to be described shortly. The completion of this task is strongly recommended.

\section{XBT DEPLOYMENTS}

The scientific and operational communities deploy several tens of thousands of XBTs, data of which approximately 25,000 XBTs every year are distributed in real- or delayed-time. In a typical year $50 \%$ are deployed in the Pacific Ocean, 35\% in the Atlantic Ocean and $15 \%$ in the Indian Ocean. Profiles from about $90 \%$ of the XBT deployments are transmitted in real-time, which represent approximately $25 \%$ of the current real-time vertical temperature profile observations (not counting the continuous temperature profiles made by some moorings).

A comparison between the recommended and actual transects and deployment modes reveal that most transects are being carried out as recommended by 
OceanObs'99. However, a few deployments are being done along transects that were not recommended, a few transects that were recommended have no deployments, and only a small number of recommended transects are being partly done. The reasons for these few changes are related to logistical problems, lack of financial support, or due to the revision of science and/or operational objectives.

\subsection{Low Density transects}

In view of the implementation of the Argo Program and of the availability of satellite altimetry data, the international SOOP community decided in 1999 to gradually phase out the transects made in LD mode, and to maintain and enhance the transects in HD and FR modes. This reduction was to be made if observations from Argo floats and satellite altimetry revealed that they could reproduce the same type of upper ocean thermal signals revealed by those from XBTs deployed in LD mode. Nevertheless, the actual reduction in LD sampling started in 2006 and without this type of study being finalized. Several LD transects were dropped and others were converted to FR transects. The reasoning behind these selections was two fold: 1) To keep the transects that had been operating the longest, and 2) To maintain transects (mostly meridional) that cross the Equator and that are located in the subtropics in view of the Seasonal to Interannual emphasis for the use of the XBT observations. Some LD transects were dropped before Argo was fully implemented and before comparisons were completed as was recommended by OceanObs'99.

Low density transects have both operational and scientific objectives, included but not limited to:

- Initialize seasonal to interannual forecast models.

- Investigate intraseasonal to interannual variability in the tropical oceans.

- Measure temporal variability of boundary currents.

- Investigate historical relationship between sea height and upper ocean thermal structure.

Illustrative examples of applications of XBT observations, primarily from LD mode, are:

- Initialize seasonal to interannual forecast models. Operationally, forecast skills of tropical Pacific SST were compared with the National Centers for Environmental Prediction (NCEP) coupled general circulation model [6]. They used different initial conditions, either assimilating subsurface data from XBTs and the TOGA-TAO buoys or not assimilating subsurface data. These experiments showed that assimilation of observed subsurface temperature data in the initial conditions, especially for summer and fall starts, results in significantly improved forecasts for the NCEP coupled model. This work also concluded that because of the more extensive temporal and spatial coverage from the TAO buoys, the combination of both buoys and XBTs resulted in a significant increase in forecast skill for the NCEP coupled model. Scientifically, XBTs were used to describe and analyze El Nino/La Nina events between 1982-1992 [7]. Successful forecasts during this period were attributed to upper ocean heat content changes in the western tropical Pacific that preceded ENSO events of the same sign and the ability to monitor these changes through use of subsurface observations. XBT observations were among the data used in these forecasts. Less successful forecasts in the following decade were attributed to different subsurface temperature variability also measured in part by XBTs, and not captured by existing forecast models.

- The time series of the position of the Gulf Stream beginning in the early 1950s obtained by combining mechanical bathythermograph data with XBT data along AX10 (Fig. 13 in [5]]. The results agreed with Gulf Stream positions over a $1000 \mathrm{~km}$ swath previously developed [8]. These results also showed that the meridional migrations of the Gulf Stream were closely correlated with the North Atlantic Oscillation (NAO) on decadal time-scales (Fig.13 in [5]). The axis translations were also similar to anomalies in Gulf Stream upper layer transport and east-west extension of the Gulf Stream southern recirculation gyre.

- The long-term evolution of the volume and spatial extension of the warm waters of the western equatorial Pacific Ocean in relation to interannual and decadal variability of ENSO. XBT observations were used to show that the Warm Pool volume expanded drastically during the past decades, a modification that may represent up to a $60 \%$ increase of the Warm Pool volume [9] and [10]. XBT observations were also used to show that changes in the surface and subsurface conditions of the warm waters of the equatorial Pacific are important to local air-sea interactions [11] and to maintain the heat buildup prior to $\mathrm{El} \mathrm{Nino}$ development [12] and [13].

- In a study of all available XBT observations from 1993 until 1999 it was observed that altimeterderived sea heights are not always directed correlated to dynamic height [14] and [15].

\subsection{Frequently Repeated transects}

The FR transects cross major ocean currents systems and thermal structures with particularly high temporal variability. In some cases, for currents near a 
continental boundary extra profiles are made when crossing the $200 \mathrm{~m}$ depth contour to mark the inshore edge of the current. The FR transects are selected to observe specific features of thermal structure (e.g. thermocline ridges), where ocean atmosphereinteraction is strong. Estimates of geostrophic velocity and mass transport integrals across the currents are made using climatological salinity profiles and by low pass mapping of temperature and dynamical properties on the section. Frequent sampling is recommended in regions that have strong intra-seasonal variability to reduce aliasing. The FR transects must be on well defined shipping routes so that the same transect is very nearly covered on each repeat-transect. The prototypes of FR transects were IX01 and PX02, which now have time series extending more than 20 years. IX01, the earliest transect, which runs from Fremantle to Sunda Strait, Indonesia, began in 1983 and has been sampled at 18 times per year most of the time since 1986. IX01 crosses the currents between Australia and Indonesia, including the Indonesian Throughflow and has been used in many studies of the Throughflow and the Indian Ocean Dipole. Most of the implemented and analyzed FR transects are located in the Indian Ocean and Indonesian Seas where the intra-seasonal variability is strong.

The CLIVAR/GOOS Indian Ocean Panel (IOP) reviewed XBT sampling in the Indian Ocean and prioritized transects according to the oceanographic features that they monitor [16]. The highest priority was given to transects IX01 and IX08. The IOP recommended weekly sampling on IX01 because of the importance for monitoring the Indonesian Throughflow and to resolve the strong intra-seasonal variability in the region. Data obtained from IX08 is used to monitor flow into the western boundary region, and the Seychelles-Chagos Thermocline Ridge, a region of intense ocean-atmosphere interaction at inter-annual time scales [17] and [18]. IX08 has proven to be logistically difficult and, therefore, an alternate transect may be needed. The oceanographic features that need to be observed with FR sampling on IX06, 09, 10, 12, 14 and 22 (Fig. 1) are identified in the IOP report.

The scientific objectives of FR transects and recent examples of research targeting these objectives are:

- Initialize seasonal to interannual forecast models.
- Measure the seasonal, interannual, and decadal variation of volume transport of major ocean currents [19], [20], [21] and [22].

- Characterization of seasonal and interannual variation of thermal structure and their relationship with climate and weather [23], [24], [25], [26], [27], [28] and [29].

- Identify the relationship between sea surface temperature, depth of the thermocline and ocean circulation at interannual to decadal timescales [30], [31], [32] and [25].

- Study of Rossby and Kelvin wave propagation [33] and [34].

- Validation of variation of thermal structure and currents in models [35], [36] and [37].

The FR samplings are designed to produce wellresolved monthly time series of thermal structure along transects. Using IX01 as an example, the mean thermal structure (Fig. 2) indicates the generally westward flow in the deeper part of the thermocline, and a shallow $(<150 \mathrm{~m})$ eastward shear [38]. The strongest variability in temperature is at the northern end of the transect near Indonesia (Fig. 2, top right). The temperature sections were used to understand the relationship of interannual variation in transport of Indonesian Throughflow to El Nino Southern Oscillation [28]. An example of time-variation of temperature at the north end of IX01 (Fig. 2) clearly shows the strong, subsurface upwelling associated with the start of the Indian Ocean Dipole (IOD) events of 1994 and 1997, before the start of surface cooling. These and the other FRX time series have been used to understand how subsurface thermal structure varies across the Indian Ocean during Indian Ocean Dipole (IOD) events [39] and [26], and more recently, combined with coupled models to understand predictability of the IOD [40]. Use of FR lines in the Indonesian region to study the Indonesian Throughflow [38], [28], [33] and [41] is discussed in the Indian Ocean Community White Paper [42]. 

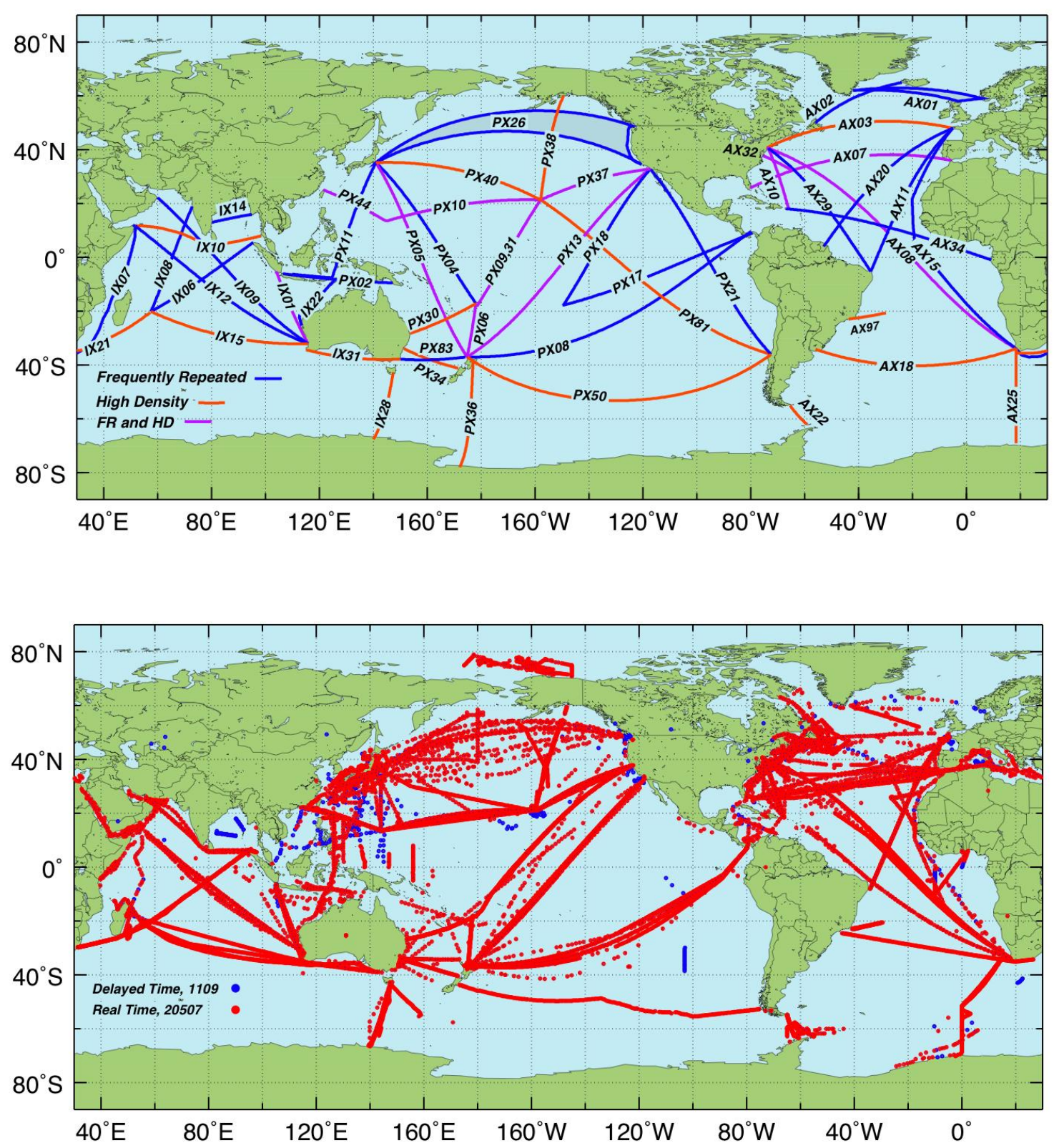

Figure 1. (top) XBT network containing OceanObs99 recommendations [1] and current proposed transects. (bottom) XBT observations transmitted in (red) real-and (blue) delayed-and real-time in 2008. The real-time data were obtained from the Global Telecommunication System (GTS) and from the Coriolis data center. The delayed-

time data were obtained from the Global Temperature and Salinity Profile Programme (GTSPP) managed by NOAA/NODC (National Oceanographic Data Center).

\subsection{High Density transects}

The HD transects extend from ocean boundary (continental shelf) to ocean boundary, with temperature profiling at spatial separations that vary from 10 to $50 \mathrm{~km}$ in order to resolve boundary currents and to estimate basin-scale geostrophic velocity and mass transport integrals. Most HD transects are carried out 4 times per year, and many now have time-series extending for more than 15 years. PX06 (Auckland to Fiji), which began in 1986, is the earliest HD transect in the present network 

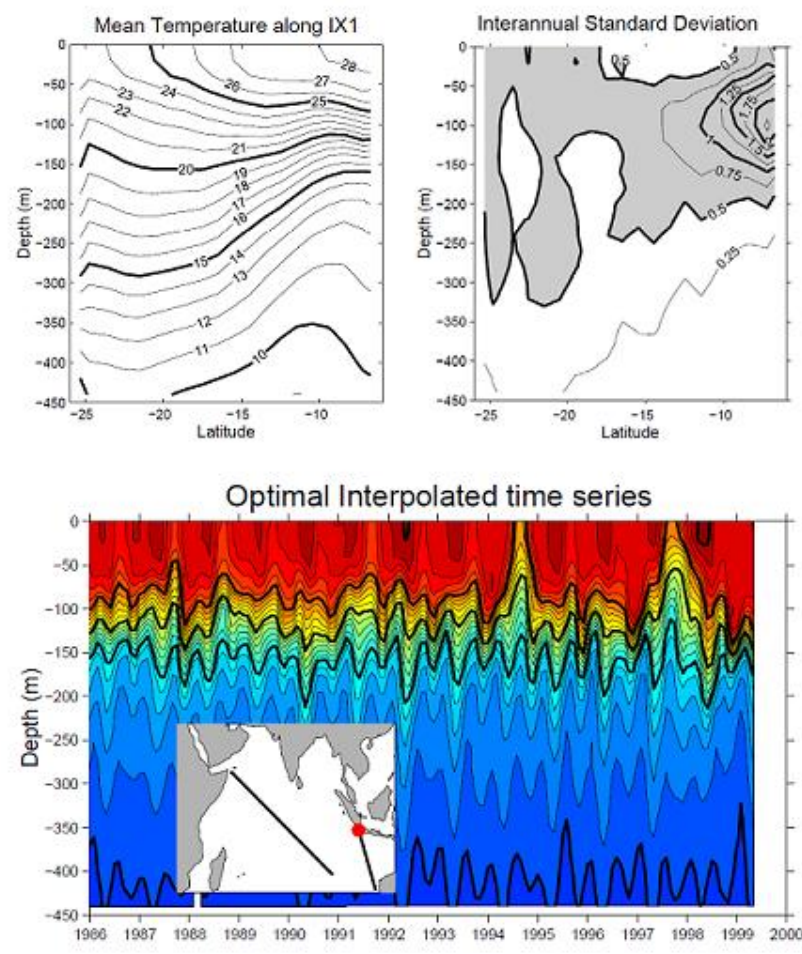

Figure 2. (top left) Mean and (top right) standard deviation of temperature on IX01. (bottom) Temperature on IX01 1985 to 1999.

with more than 90 realizations. The scientific objectives of HD sampling, and examples of research targeting these objectives are:

- Measure the seasonal and interannual fluctuations in the transport of mass, heat, and freshwater across transects which define large enclosed ocean areas and investigate their links to climate indexes [43], [44], [45], [46] and [47].

- Obtain long time-series of temperature profiles at approximately repeated locations in order to unambiguously separate temporal from spatial variability [54].

- Determine the space-time statistics of variability of the temperature and geostrophic shear fields [55].

- Provide appropriate in situ data (together with Argo profiling floats, tropical moorings, air-sea flux measurements, sea level etc.) for testing ocean and ocean-atmosphere models.
- Determine the synergy between XBT transects, satellite altimetry, Argo, and models of the general circulation [56] and [57].

- Identify permanent boundary currents and fronts, describe their persistence and recurrence and their relation to large-scale transports [58], [59] and [60].

- Estimate the significance of baroclinic eddy heat fluxes. [61].

Some transects are currently inactive due to implementation issues, usually related to ship recruitment, but some alternative transects are being carried out in their place, such as PX50/PX08 and AX18/AX17 (AX17 runs from Cape Town to Rio de Janeiro). Other transects, such as IX21 and IX15, have had multi-year interruptions. Detailed sampling histories and data from some of the open ocean HD transects are available at http://www-hrx.ucsd.edu and http://www.aoml.noaa.gov/phod/hdenxbt. Data along individual transects are also made available through these web sites. Several transects have been initiated in the Mediterranean Sea, such as MX01 (DamiettaMessina/Malta), MX02 (La Spezia-Gibraltar), MX04 (Malta-La Spezia; Genoa-Palermo), and MX05 (TriesteDures-Bari) although their data are not currently being transmitted in real-time. Data from current HD transects are mostly used for research purposes and that alone represents a strong argument for their continued maintenance. Four illustrative examples are presented here that show key scientific results obtained from HD transects:

\subsubsection{Temperature and geostrophic current variability in the southwest Pacific Ocean.}

XBT profiles obtained along PX06 provide typical results from HD transects, such as the 20-year mean and variance of temperature [62], mean geostrophic velocity, and time series of net geostrophic transport (Fig. 3).

The high value of this long time-series is seen in several ways. First, the 20-year mean velocity shows that the eastward flow from the separated western boundary current occurs in distinct permanent filaments (Fig.3) [59], demonstrating the banded nature of the mean velocity field; these filaments are also visible in all 5year subsets. Second, the existence of minima in temperature variance at both ends of this transect indicates that geostrophic transport integrals spanning the entire transect have less variability than any partial 

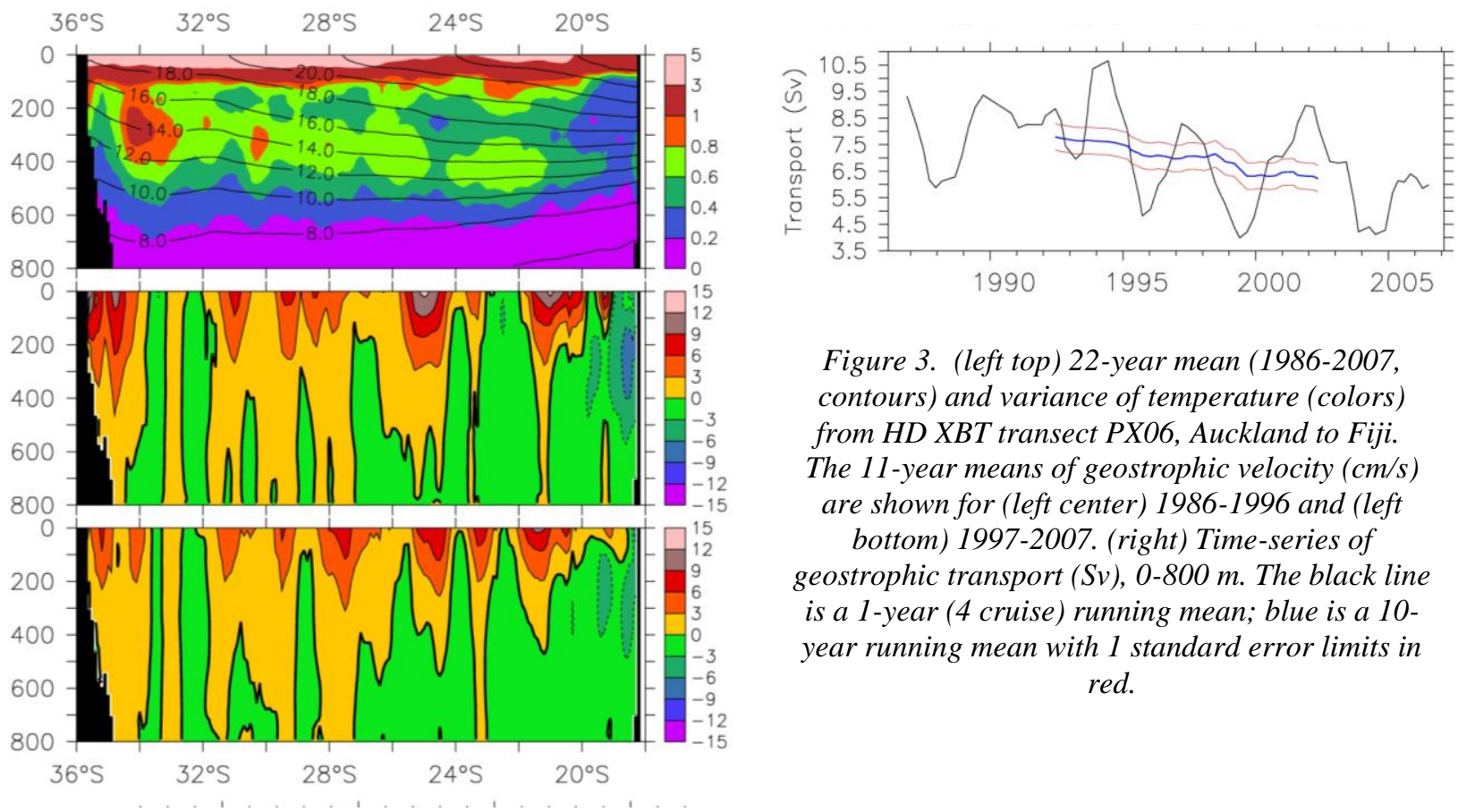

Figure 3. (left top) 22-year mean (1986-2007, contours) and variance of temperature (colors) from HD XBT transect PX06, Auckland to Fiji.

The 11-year means of geostrophic velocity $(\mathrm{cm} / \mathrm{s})$ are shown for (left center) 1986-1996 and (left

bottom) 1997-2007. (right) Time-series of geostrophic transport ( $\mathrm{Sv}$ ), 0-800 m. The black line is a 1-year (4 cruise) running mean; blue is a 10year running mean with 1 standard error limits in red.
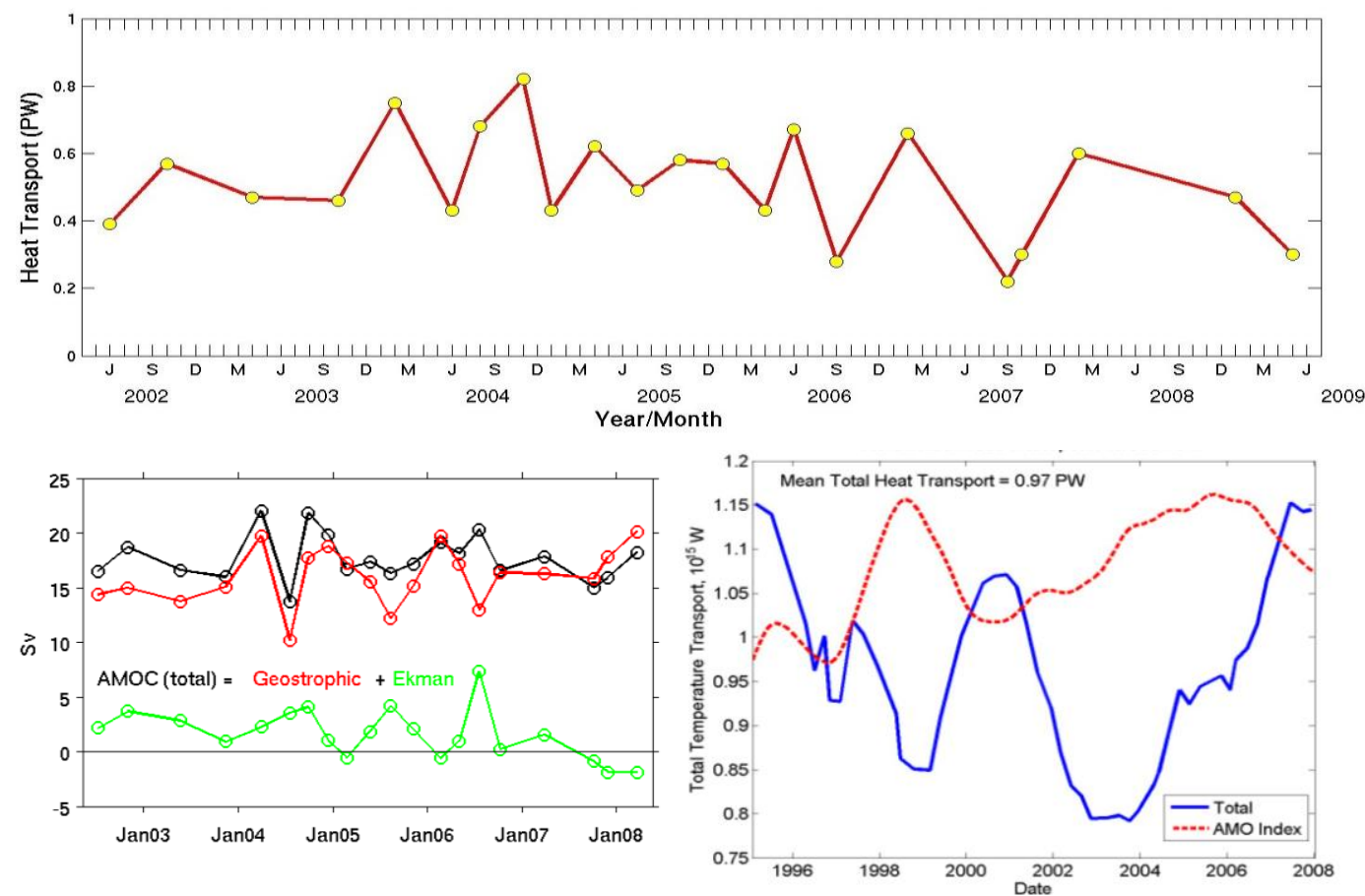

Figure 4. (top) Heat transport estimates in the South Atlantic across 35 S using data from the AX18 transect. (bottom, left) Time series of the AMOC (black) estimated from AX18 and contributions from the geostrophic (red) and Ekman (green) components [47]. (bottom, right) Northward heat transport (blue line) across the high density (HD) transect AX07 that includes coast to coast observations from Gibraltar to Miami compared to the Atlantic Multidecadal Oscillation (AMO) index (red dashed line). 
integrals. Third, the HD-XBT network design, which in this particular case encloses a region with boundary-toboundary sampling, provides closed mass and heat budgets for the upper ocean [44]. Fourth, the transport time-series shows variability with a period of about 4 years and decadal trend to lower eastward transport. This change is consistent with decadal changes in wind stress that are believed to have caused the East Australian Current to extend farther southward [24]. Finally, this transect has also contributed to understanding the formation, spreading, characteristics and variability of South Pacific Subtropical Mode Water [63], [64] and [65].

\subsubsection{Atlantic Meridional Overturning Circulation studies.}

In the Atlantic, the two zonal HD transects AX18 and AX07 are being used to assess the meridional oceanic heat flux. The AX18 transect was originally designed to monitor the upper limb of the Atlantic Meridional Overturning Circulation (AMOC) as it enters the South Atlantic at approximately $35^{\circ} \mathrm{S}$, between South Africa and South America and it is now also used as the core of the observations to monitor the AMOC meridional heat transport in the South Atlantic [46] and [45]. During the period July 2002 - September 2009, twenty-two realizations of this transect have been carried out. Results from these HD transect show that the northward heat transport across $35^{\circ} \mathrm{S}$ is approximately $0.51+/-0.16$ PW (Fig. 4, top). A clear seasonal cycle was found for the geostrophic and Ekman heat transport, which have similar amplitude but are close to $180^{\circ}$ out of phase, therefore explaining the small seasonal cycle in the total northward heat transport. This northward heat transport is directly linked to the strength of the MOC that shows a similar out of phase relationship between Ekman transport and Sverdrup transport (Fig. 4, left). In the north Atlantic, the HD transect AX07 (at approximately $30^{\circ} \mathrm{N}$ ) is being analyzed to estimate the northward heat transport. Results have shown that the northward transport (computed using the methodology introduced by [46]) has a remarkable out of phase relationship to important climate indices, such as the Atlantic Multidecadal Oscillation (AMO). Results also show that the net northward heat transport through the center of the subtropical gyre in the North Atlantic is negatively correlated to the AMO index for time scales longer than 2 years (Fig.4, bottom right). The AX07 transect is also being used to estimate eddy heat transports in association with the Rapid/MOCHA (Rapid Climate Change Programme/Meridional Overturning Circulation and Heatflux Array) Program, which is in place to measure the MOC at $26^{\circ} \mathrm{N}$.

\subsubsection{Variability of the Antarctic Circumpolar Current south of Africa.}

The near-meridional HD XBT transect AX25 (between Cape Town and Antarctica) provides detailed information on the varying physical structure of the upper ocean across the widest 'chokepoint' (>4000 km) of the Southern Ocean. These observations are extremely important due to the scarcity of hydrographic observations in this region. In recent years, techniques that include the incorporation of satellite altimetry observations have been employed to provide additional oceanographic information from XBT profiles. Along the AX25 transect, XBT data are used to construct empirical relationships whereby baroclinic transport estimates of the Antarctic Circumpolar Current (ACC) can be derived from altimetry data alone. These estimates have been a major aim of oceanographers in the past. For example, these methods provide a 16-year long, weekly time series of ACC transports (Fig.5), which reveals the internal variability of the ACC system. Additionally, XBTs in HD mode have uncovered, in more detail, the fine scale jets and fronts that make up the total circumpolar flow in this region [49]. Interestingly, results have shown that the Subantarctic Front contributes to over $50 \%$ of the total

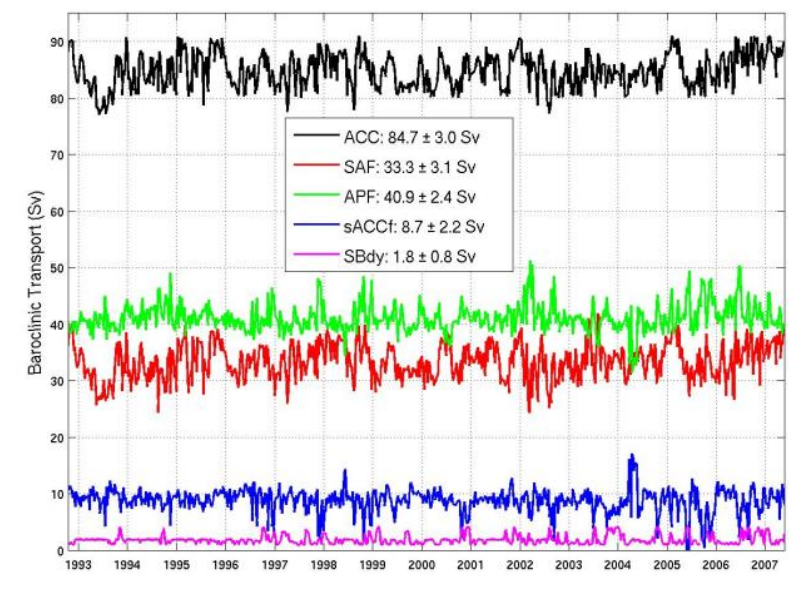

Figure 5. Time series of baroclinic transport estimates, relative to 2500 dbar, for Antarctic Circumpolar Current front and for the whole Antarctic Circumpolar Current domain between 1992 and 2007 [49]. These transports are estimated from altimetry data using proxy techniques constructed from CTD and XBT data along the AX25 hydrographic transect. The legend depicts the mean and standard deviation of the transport time series for each respective domain. ACC $=$ Antarctic Circumpolar

Current, $S A F=$ Subantarctic Front, $A P F=$ Antarctic

Polar Front, $s A C C f=$ Southern Antarctic Circumpolar Current front, and SBdy=Southern Boundary of the ACC. 
transport variance of the ACC over the time series, even though its net transport contribution is less than other fronts. In time, supplementary XBT deployments will be used to validate and improve this range of methods that are required in data sparse regions and to investigate variability from seasonal to interannual time scales.

\subsubsection{Temperature and geostrophic current variability in the Bay of Bengal.}

Utilizing a twenty year (1989 - continuing) time series of XBT observations collected along IX14 by the National Institute of Oceanography, India, surface

and subsurface temperature changes were used to investigate a) if the subsurface North Indian Ocean is affecting a possible amelioration of the observed increase in SST, and b) if the Arabian Sea and the Bay of Bengal exhibit opposing behavior with respect to ocean heat content, with one cooling and the other warming, resulting in no obvious trend in ocean heat content. Preliminary results show that temperature anomalies [for the red shaded box in Fig. 6a] at the sea surface and at 600 meters depth exhibit significant increasing linear trend (Fig. 6b), while the temperature anomaly at 100 meters (nearly representing thermocline depth) exhibits strong year to year variability with no long term trends (Fig. 6c). The use of this consistent data set removes the complication of separating real physical change in the temperature structure of the Bay of Bengal from changes that may be introduced by differences in instrumentation and collection procedures. Using the two datasets can independently support results, at least for the last few years. Maintaining these transects in the Bay of Bengal will extend this work into the future and provide crucial information on climate change in the North Indian Ocean.

\section{DATA MANAGEMENT}

The data management activities of SOOP continue to be undertaken in collaboration with GTSPP. The GTSPP is a joint program of the International Oceanographic Data and Information Exchange committee (IODE) and the JCOMM. The Integrated Science Data Management of Canada accumulates near real-time data from several sources via the GTS, checks the data for several types of errors, and removes duplicate copies of the same observation. These operations occur three times per week before passing the data on to the Continuously Managed Database (CMD) maintained by the U.S. National Oceanographic Data Center (NODC). The data flow into the CMD is through a "Delayed Mode Quality Control (QC)" process. This process includes format conversion, format-consistency test, authority tables' check, and duplicate check for the GTSPP database. The NODC replaces near real-time records with higher quality delayed-mode records as they are received and populates the GTSPP data on-line through the GTSPP Web site at:

http://www.nodc.noaa.gov/GTSPP. The unique features of GTSPP include: (1) unify all temperature (T) and salinity (S) profile data into a common structure and therefore a common output, which is inter-operational and extendable, (2) set standards for quality control of T and S profile data, (3) document data processing history, and (4) provide ship operators with monthly reports of data quantity and quality assessment, and (5) carry complete metadata descriptions of every record. Readers should refer to the Community White Paper describing the GTSPP operations for greater detail.

The World Ocean Database (WOD) is updated every 3 months directly from the GTSPP database to incorporate all newly added SOOP XBT data and changes to existing data. Additional quality control steps are performed on the data in WOD and any problems found are reported back to GTSPP. WOD also incorporates XBT and other ocean profile data from other sources to form a comprehensive quality controlled database of historical and recent temperature, salinity (and other ocean variables) profile data as possible. WOD data are available through www.nodc.noaa.gov, using the WODselect data selection tool.

\section{XBT BIASES}

The bulk of XBT temperature profiles are collected using probes manufactured by Sippican Incorporated (now Lockheed Martin Sippican). Uncertainties in the determination of the XBT depth are the most important source of error in XBT temperature profiles [20] although other sources of error exist (e.g. temperature biases and transient effects at air-water transition). XBTs determine the depth of the temperature observations indirectly from a time trace converted into depth using a fall-rate equation (FRE). This FRE results from a simple dynamical model, where the net buoyant force is balanced by hydrodynamic drag proportional to the square of the probe speed [66] and [67]. Systematic errors in the computed XBT depths have been identified since the mid 1970s. Early comparison studies between simultaneous XBTs and Conductivity Temperature Depth (CTD) casts found a small positive bias above the thermocline, while a much larger negative bias for depths below [68], [69], [70] and [71] demonstrating the limitations of the original FRE. Evidence of surface offsets associated with initial transients has also been found [72] and [73]. It was not until the 1990s that the impact of systematic errors in XBT profiles was fully recognized, even if the occurrence of XBT bad (but hard to identify) measurements was underlined since 1980 [74]. 

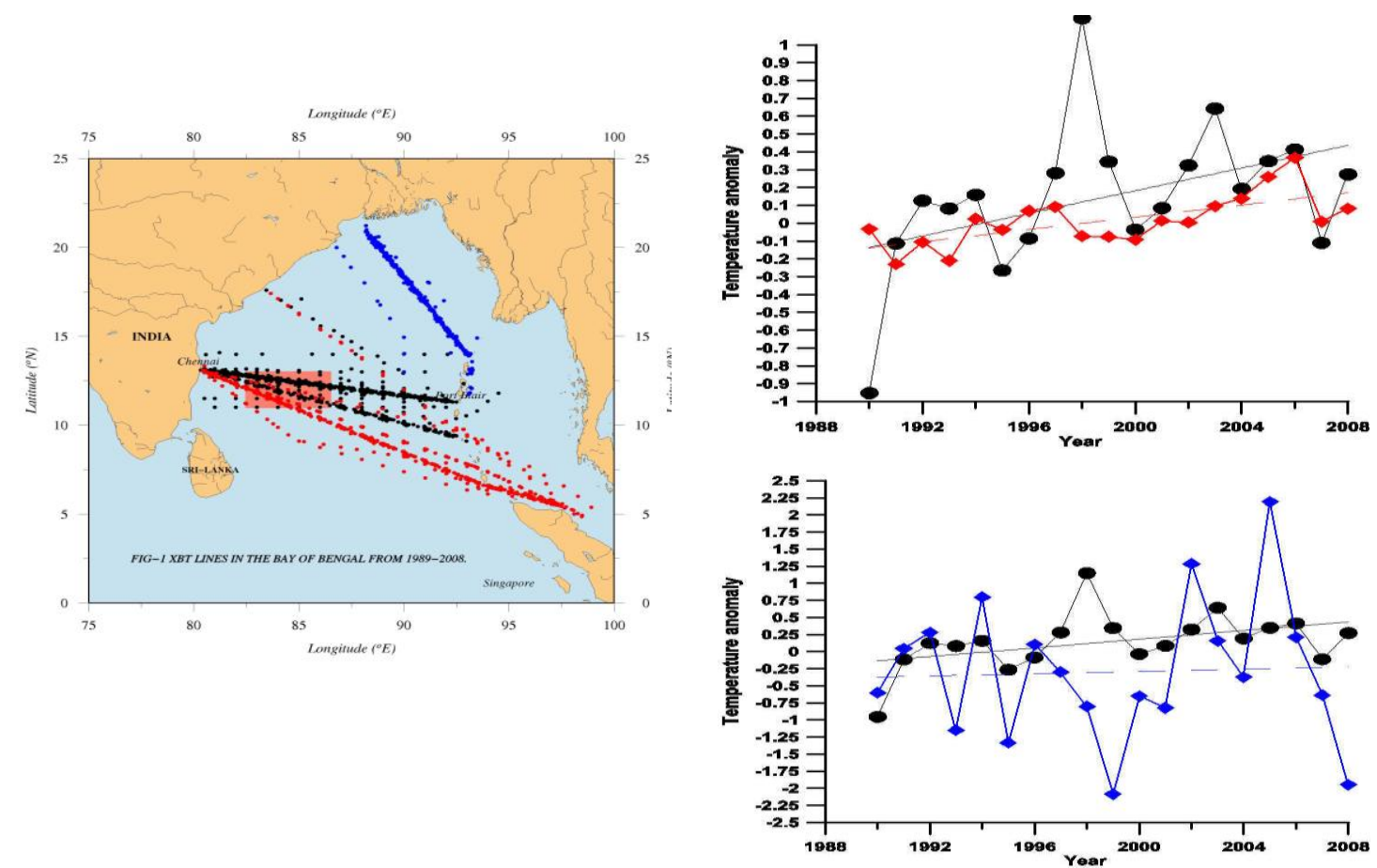

Figure 6. (left) XBT transects in the Bay of Bengal (1989-2008); year-to-year changes in temperature anomalies for the shaded box in the map (right, bottom) at the surface (black) and 100m (blue); and (right, top) for the surface (black) and $600 \mathrm{~m}$ deep (red).

Sippican adopted new coefficients for the FRE after a comprehensive analysis of research-quality CTD and XBT data [75]. This study showed that the manufacturer coefficients in the FRE resulted in depths that were too shallow, producing a cold temperature bias in most of the water column. As a result a stretching factor of 1.0336 was applied to depths estimated using the original manufacturer FRE.

A time-varying positive temperature bias was recently found by globally comparing climatologies derived from XBT and CTD/bottle observations [76] (Fig. 7a). This result was later confirmed and attributed to fallrate variations due to minor manufacturing changes over time [20]. A time variable depth correction factor was recommended in order to eliminate the hypothesized error. However, a recent study of the global XBT database shows that: 1) using the same correction factor for all depths (Fig. 7b-c) does not allow effective elimination of the total temperature bias over the whole depth range; 2) the application of a constant correction factor [75] (Fig. 7b) or time varying factor [20] (Fig.7c) increases the total warm bias compared to the original fall rate equation. This study showed that the time-dependent XBT bias may be explained as a superposition of a temperature bias due to systematic depth error (Fig. 7e) and of the pure thermal bias (Fig. 7f), with the latter exhibiting considerable variation with time and a weaker correlation with water temperature. While all studies indicate time-dependent temperature errors in XBT observations, the attribution of these errors remains unclear from these studies. However, there is robust evidence that both fall-rate and pure thermal biases are present in the XBT data. Because the ocean is thermally stratified, fall-rate errors and pure thermal errors cannot be separately identified when comparing climatologies. Moreover, massive amounts of data are needed to average the non-collocated observations in order to detect small deviations in the mean of the climatologies. Only side-by-side experiments, such as collocated XBT and CTD casts, can be used to unambiguously separate the two types of errors. Recent analyses of side-by-side data covering the 1986-2008 period show strong evidence of time-dependent changes in the XBT fall-rate. These studies provide strong evidence that the Hanawa correction was adequate during the 90s; however, the original Sippican FRE coefficients are accurate for the years after 2008. Despite the lack of consensus in the attribution of the origin of the XBT biases mentioned above, the application of any of the corrections results in comparable estimates of global ocean heat uptake and a reduction of spurious decadal variability. A final correction of XBT biases to historical data consistent with both side-by-side experiments and climatological CTD/bottle/Argo data is not expected to yield different than the already existing corrections to globally averaged heat storage estimates.

XBT profiles currently make up to $25 \%$ of the current global temperature profile observations, XBTs have 
provided over 30 years (1970-2000) a large (>25\%) fraction of the ocean observing system for upper ocean thermal observations, and in addition are currently the most important platform for monitoring ocean heat transport. Thus attributing the origin of the biases is important to understand potential biases that may arise in the future. Additionally, systematic biases between

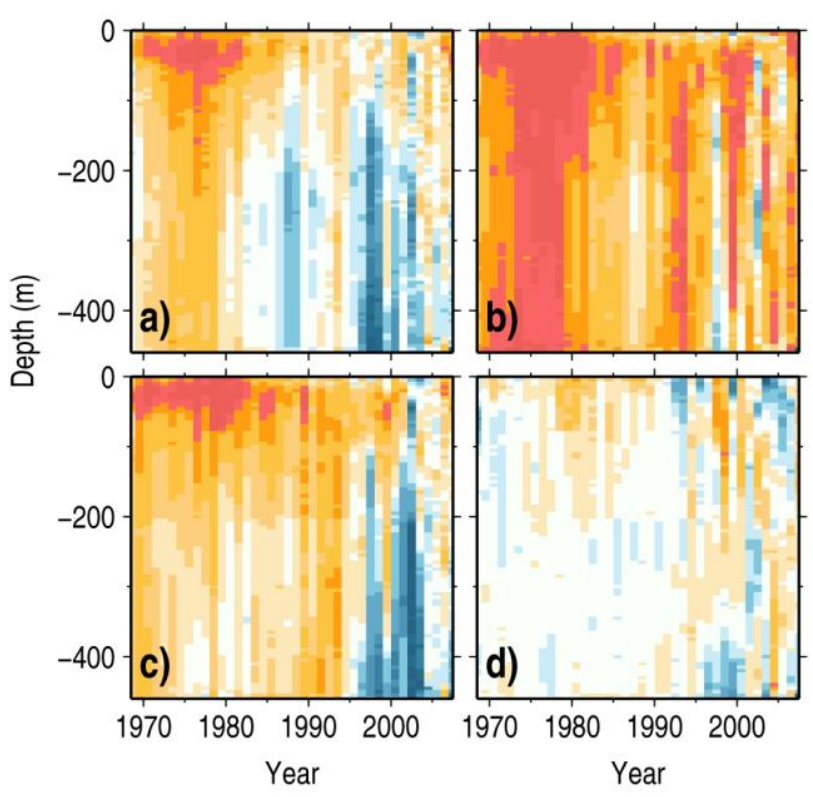

$-5.000-0.275-0.225-0.175-0.125-0.075-0.0250 .0250 .0750 .1250 .1750 .2250 .2755 .000$ observing systems with disparate quality capabilities, such as Argo and XBTs, need to be assessed to avoid introducing future spurious climatic signals in heat storage when data from the two systems are combined [77].
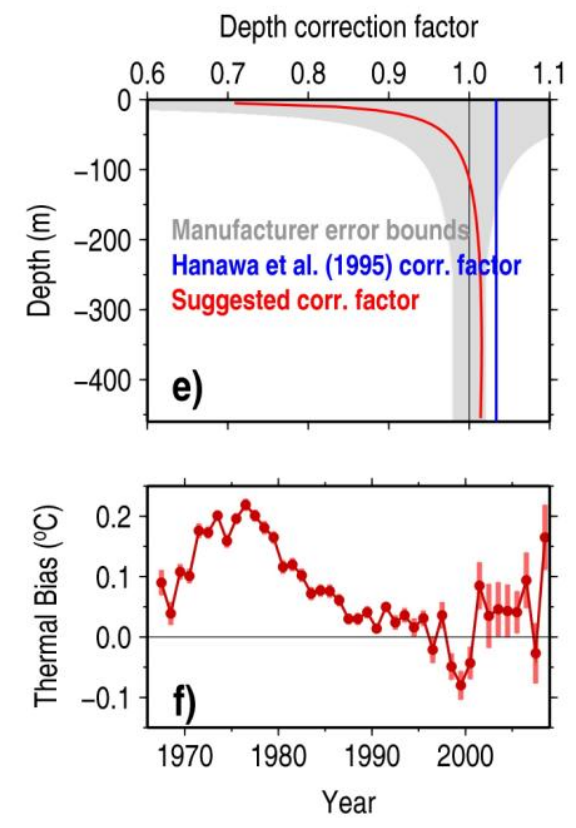

Figure 7. Time-varying temperature bias comparing XBT and CTD bottle observations (a) using original manufacturer fall rate equation, (b) XBT depth correction by [74], (c) time-varying depth corrections by [41], (d) temperature and depth corrections according to Gouretski and Reseghetti (2009, submitted); (e) XBT sample depth uncertainty and depth correction factors from [74] (in blue) and Gouretski and Reseghetti (submitted, 2009) (in red); and (f) estimate of the time-varying thermal bias. All results refer to XBT types T-4 and T-6.

Despite the substantial progress that has been made in recent years to assess the origin and magnitude of this bias and to identify other systematic errors in XBT profiles, more work is still needed to improve the quality of XBT data for climate applications. These efforts should be focused on: 1) Monitoring changes in the fall-rate characteristics of the various types of XBT probes, 2) Confirmation that the origin of theses changes results from manufacturing variations as hypothesized by [20], even when the manufacturer confirm the stability of the components of the XBT probes, with the exception of the wire coating process that has introduced a slightly decrease in wire linear density since 1996, 3) Exploration of other potential sources of systematic errors, such as surface offsets, temperature biases in the thermistor, bias due to coupling among cable, probe and electronic devices, 4) Evaluation of the possible influence of water temperature on the FRE coefficients, as recently proposed for T-5 probes [78] and XCTDs [79], confirming early suggestions after tests in Antarctic waters [80], and 5) Assessment of the origin of random errors, as it remains unclear whether surface offsets are systematic or random [81]. This offset could result from hydrodynamical transients during the initial seconds of the descent influenced by the height from which XBTs are launched, the angle of impact of the XBT in the water [66], or by the ship speed. These parameters should be included in the XBT metadata to facilitate future studies about these issues. The better understanding and evaluation of XBT biases will justify their use in 
climate studies, such as monitoring global trends in heat content.

Improving the XBT technology could be an alternative and effective path to reducing future errors and biases. During the 90s, an attempt was made to do include pressure sensors in the XBTs. The prototype included a pressure switch that recorded the pressure (i.e. depth) at fixed depths during the descent of the probe. These "real" depth observations could then be used for calibrating the depth estimated using the FRE. This effort was not successful due to several technological limitations that dramatically reduced the shelf life of the XBT. Recent technological advances in cost and reliability of pressure sensors and digital systems could now make this prototype viable. Moreover, a few pressure switches strategically activated during the descent could substantially reduce the depth errors in both fall-rate and surface offset.

\section{SIMULTANEOUS OCEAN OBSERVATIONS: THE OLEANDER PROJECT}

Ships from the SOOP provide an excellent opportunity for obtaining data from various observational platforms along repeated transects. The R/V Oleander is a container vessel that operates the AX32 transect (Fig. 1) twice a week, between Port Elizabeth, NJ, and Hamilton, Bermuda. Besides deploying XBTs since 1976, the Oleander operates a continuous plankton recorder (CPR) since 1975, an Acoustic Current Doppler Profiler (ADCP) since 1990, a TSG since 1991, and a pCO2 system since 2006. This operation is maintained jointly between the University of Rhode Island, the State University of New York at Stony Brook, and NOAA (Northeast Fisheries Science Center and Atlantic Oceanographic and Meteorological Laboratory). The ADCP measures upper ocean currents from the surface to 200-400 m depth depending upon weather, load factor, and backscatter material. This project has provided the longest temperature time series of the Gulf Stream. As such it is now in a position to address decadal and longer variability in the structure and variability of currents, including transport [82], [83]. Several factors make this route special. 1) It crosses four separate hydrographic regimes, the continental shelf, the Slope Sea, the Gulf Stream, and the northwest Sargasso Sea. Each exhibits quite distinct characteristics. 2) It also crosses the Gulf Stream at a location where the meandering is relatively modest making both space and time averaging particularly efficient. As such, it provides an excellent monitoring of the Gulf Stream transport shortly after it separates from the coast. 3) The Slope Sea and shelf segments provide an excellent window into the fluxes from the Labrador Sea. Significantly, these fluxes exhibit a factor 2 range in transport variations (on interannual timescales) that appear to be related to the state of the North Atlantic
Oscillation. 4) The Sargasso Sea segment also exhibits factor two variations in transport, but these appear to exhibit somewhat faster (interannual) timescales. Ongoing and near-future research include 1) studies of the horizontal wave number spectrum of velocity, 2) further research into the discovery of a westward flowing jet in the Slope Sea, 3) an intercomparison of estimated sea level from a (geostrophic) integration of ADCP velocity and sea level from altimetry at cross-over points between the Oleander and two or three satellite track lines, and 4) an update on low-frequency variability and possible trends in Gulf Stream transport.

\section{THE FUTURE OF THE XBT NETWORK AND OF THE SHIP OF OPPORTUNITY PROGRAM}

The XBT network involves the work of many components of the international field observations and science communities. The XBT network presented here (Fig. 1) supports the recommendations of OceanObs'99 and includes several transects that the scientific community has added during the last 10 years. Some transects may be difficult to occupy continuously due to logistical and budgetary constraints; however, they are kept as recommendations based on the justifications given by OceanObs'99 and by evidence of their scientific contributions.

The FR transects have produced noteworthy scientific insights, particularly in the eastern Indian Ocean and the Indonesian region, and represent some of the longest running time series of basin-scale ocean-structure. Nevertheless, many of the global FR transects have not been taken up by the scientific community. The opinion of these authors is that JCOMM should sponsor an analysis to assess the value of existing and proposed FR transects, in particular to determine the optimal sampling frequency and distance between consecutive deployments in these transects.

With the full implementation of Argo and continued altimetry observations, the role of the XBTs and their impact on ocean analysis and seasonal forecasts should be re-assessed using numerical modeling and statistical analysis. Regarding real-time ocean analysis, it is important to consider that some redundancy in the observing system is required, especially to assist automatic quality control procedures. For instance, having XBT data in the vicinity of Argo floats can help to detect errors in one or the other instrument.

Ten years after OceanObs'99, the High Density XBT network continues to increase in value, not only through the growing length of decadal time-series, but also due to integrative relationships with other elements of the ocean observing system, including: 
- The implementation of global broad scale temperature and salinity profiling by the Argo Program underlines a need for complementary high-resolution data in boundary currents, frontal regions, and mesoscale eddies. HD XBT transects together with Argo provide views of the largescale ocean interior and small-scale features near the boundary, as well as of the relationship of the interior circulation to the boundary-to-boundary transport integrals.

- Fifteen years of continuous global satellite altimetric sea surface heights matched by contemporaneous HD sampling on many transects. The sea surface height ( $\mathrm{SSH}$ ) and the subsurface temperature structure that causes most of the SSH variability are jointly measured and analyzed [57].

- Air-sea flux estimates in large ocean areas complement the heat transport estimates from HD transects and the heat storage estimates from Argo.

- Improved capabilities in ocean data assimilation modeling allow these and other datasets to be combined and compared in a dynamically consistent framework.

- Integration of different observations as obtained from XBTs, TSGs, CPR, and ADCP aboard the $\mathrm{R} / \mathrm{V}$ Oleander along the transect $\mathrm{AX} 32$ will be key to understanding the variability of the Gulf Stream. This type of operations could be extended to other transects. For example, AX01 across the North Atlantic subpolar gyre, where a similar mix of instrumentation is implemented on the Nuka Arctica, but currently on a nonpermanent, reviewed, project-basis. This combined sampling could provide clues on the variability of meridional heat transport in the northern limb of the thermohaline circulation of the North Atlantic, as well as on the large changes in the subpolar gyre sink of carbon dioxide.

The SOOPIP must continue fulfilling the field operations and data management of the XBT upper ocean thermal requirements established by the Global Climate Observing System (GCOS). Observations from XBTs will continue being critical in undersampled regions and even in interior seas; where the combination of hydrographic and satellite observations have proved to be critical for extreme weather studies [84], [85] and [86]. The authors of this manuscript recommend forming a Science Steering Team or Panel to discuss the scientific and operational contributions of the XBT network, address specific problems of the XBTs, such as the fall rate equation, and to evaluate the upper ocean thermal network with members of the scientific and operational communities of platforms that carry out temperature observations in the upper ocean. This team will be charged with meeting every two years to communicate scientific and operational results, to evaluate the requirements of these two communities, and to maintain a close relationship with SOOPIP for the assessment of the network implementation. The presentation of results in meetings and workshops to emphasize the importance of the XBT network in scientific studies and operational work must continue, particularly to highlight the integration of XBTs with other observational platforms and their impact in the ocean observing system.

The value of cargo ships for the deployment and installation of oceanographic scientific instrumentation has been highlighted throughout this manuscript. Given the historical and ongoing success of the SOOPIP implementing and sustaining these types of operations, it is recommended that SOOPIP continue this role with support from the international community. Furthermore, it is recommended that other observing system advisory panels that presently collaborate with SOT, such as GOSUD with SOOPIP and SAMOS with VOS and SOOPIP, also be supported. New related programs and panels that are or will be formed should be encouraged to work within the existing framework of SOOPIP and VOS to avoid unnecessary duplication of effort and to make more effective use of limited funds.

Technology will continue to play a vital role in the implementation and sustainability of the XBT network. In order to improve the HD operations, collaboration among different institutions should be increased to develop new technology during the upcoming years, including the building and testing of new autolaunchers and acquisition systems that will require less human participation.

Data management will continue to be a critical component of the XBT operations. With the implementation of the new BUFR format, special emphasis must be given to metadata, which can be used, for example, to identify systematic errors in equipment and ships. Transmission of quality controlled data in real-time will continue to be vital for assimilation in climate and weather forecast models. Given the existing different options of data formats and transmission platforms, an evaluation should be made to unify the implementation of full or subsample (inflection points or standard depths) transmissions in real-time. Real-time quality control procedures performed by different institutions will, following the Argo example, be unified. Delayed mode GTSPP data should include the full resolution data from XBTs or CTDs from the ships, or fully processed and quality controlled data from the organizations that provided the real time low resolution data to the GTS. The numbers of the delayed-mode measurements added to the archive were 12,737 and 62,252 in 2007 and 2008, respectively. GTSPP continued to improve its 
capabilities of serving the data for operations and climate research. The GTSPP data sets are available at GTSPP's Web site at http://www.nodc.noaa.gov/GTSPP/. Additionally, delayed-mode XBT data received through the Global Oceanographic Data Archeology and Rescue Program (GODAR) will be processed by the WOD. All delayed-mode XBT data will be available through both the GTSPP database and the WOD (within 90 days of processing).

\section{SUMMARY}

The authors recommend the following:

1) That the scientific community fully implement and maintain the XBT network (top Fig. 1).

2) To investigate the possibility of increasing the number of recommended XBT transects to include interior and marginal seas, such as the Mediterranean Sea and the Gulf of Mexico, where observations from other platforms are insufficient, and if the scientific and operational objectives justify their implementation.

3) To analyze and evaluate the correct temporal and spatial sampling rate for each deployment mode.

4) To carry out numerical and statistical analysis of transects in their three different modes to evaluate the effectiveness of profiling floats to reproduce climatic signals that were previously captured by XBTs in LD mode.

5) To continue the support of real-time transmissions of all XBT observations, as well as of other observational platforms (such as TSGs), into real-time data transmission systems (such as the GTS).

6) To support advisory panels such as GOSUD and SAMOS and that new similar programs and panels be structured within the existing framework of SOOPIP and VOS.

7) To support the integration of XBT observations with those of other platforms, such as satellite altimetry, TSGs, pCO2 systems, CPRs, etc, along recommended transects, as currently done in the Oleander (AX32) and Nuka Arctica (AX01) operations.

8) To support technological improvement of XBTs, launcher systems, and transmission systems.

9) To establish a community-based system and procedures of XBT calibrations based on CTDs to facilitate the comparison of XBT data every time research-quality CTD data are collected. Increased understanding and evaluation of XBT biases will justify their use in studies for which they were not originally designed, such as monitoring global heat content.
10) Support the development of an XBT probe capable of measuring pressure at selected depths.

11) To establish consistent data quality control procedures and data base management, for realand delayed-time data, following strategies recommended by the scientific community.

12) To make recommendations on the parameters (FRE coefficients, XBT model, recording device, height of platform, ship speed, etc.) that need to be included in the metadata to facilitate future XBT data quality control procedures.

13) To complete a high quality, historical and global XBT database.

14) To continue the current strong emphasis of XBT data analysis for scientific studies and increase its operational applications.

15) To support a strong presence of XBT science and operations results in scientific and operational panels and meetings.

16) To recommend the creation of an international panel for upper ocean thermal observations to support and evaluate recommendations of the integration of the different platforms, including XBTs.

\section{REFERENCES}

1. Smith, N., D. Harrison, R. Bailey, O. Alves, T. Delcroix, K. Hanawa, B. Keeley, G. Meyers, R. Molinari, and D. Roemmich (2001). The upper ocean thermal network. From: Observing the Oceans in the $21^{\text {st }}$ Century, C. Koblinsky and N. Smith, Eds, Bureau of Meteorology, Melbourne, pp. 259-284.

2. Smith, S. \& Co-Authors (2010). "The Data Management System for the Shipboard Automated Meteorological and Oceanographic System (SAMOS) Initiative" in these proceedings (Vol. 2), doi:10.5270/OceanObs09.cwp.83.

3. Kent, E. \& Co-Authors (2010). "The Voluntary Observing Ship (VOS) Scheme" in these proceedings (Vol. 2), doi:10.5270/OceanObs09.cwp.48.

4. Gould, J. and the Argo Science Team (2004). Argo profiling floats bring new era of in situ ocean observations, EOS transactions of the American Geophysical Union, 85(19).

5. Molinari, R.L. (2004). Annual and decadal variability in the western subtropical North Atlantic: signal characteristics and sampling methodologies, Progress in Oceanography, 62, 33-66.

6. Ji, M. and A. Leetmaa (1997). Impact of data assimilation on ocean initialization and El Nino prediction, Mon. Wea. Rev., 125(5), 742-753.

7. Ji, M., A. Leetmaa and V.E. Kousky (1996). Coupled model predictions of ENSO during the 1980s and the 1990s at the National Centers for Environment Prediction, J. Climate, 9(12), 3105-3120. 
8. Joyce, T. M., C. Deser, and M. A. Spall (2000). On the relation between decadal variability of Subtropical Mode Water and the North Atlantic Oscillation, $J$. Climate, 13, 2550-2569.

9. Toole J.M., Zhang H. M., Caruso M. J. (2004). Timedependent internal energy budgets of the tropical warm water pools, J. Climate., 17(6):1398-1410.

10. Cravatte, S., T. Delcroix, D. Zhang, M. McPhaden, and J. Leloup (2009), Observed freshening and warming of the western Pacific warm pool, Clim. Dyn., 33, 565-589.

11. Maes, C., K. Ando, T. Delcroix, W. S. Kessler, M. J. McPhaden, and D. Roemmich (2006). Observed correlation of surface salinity, temperature and barrier layer at the eastern edge of the western Pacific warm pool, Geophys. Res. Lett., 33, doi:10.1029/2005GL024772.

12. Meinen C, McPhaden MJ (2000). Observations of warm water volume changes in the equatorial Pacific and their relationship to El Niño and La Nina, $J$. Climate, 13, 3551-3559.

13. Maes C, Picaut J, Belamari S (2005). Importance of salinity barrier layer for the build up of El Niño, $J$. Climate, 18, 104-118. doi:10.1175/JCLI-3214.1

14. Mayer, D., M. Baringer, and G. Goni (2003). Comparison of Hydrographic and Altimetric Estimates of Sea Level Height Variability in the Atlantic Ocean, Interhemispheric Water Exchange in the Atlantic Ocean, Elsevier Oceanographic Series, 68, 23-48, Elsevier Science.

15. Mayer, D., R. Molinari, M. Baringer and G. Goni (2001). Transition regions and their role in the relationship between sea surface height and subsurface temperature structure in the Atlantic Ocean, Geophys. Res. Let., 28, 3943-3946.

16. CLIVAR Project Office (2006). Understanding The Role Of The Indian Ocean In The Climate System Implementation Plan For Sustained Observations. CLIVAR Publication Series No.100, GOOS Report no. 152, WCRP Informal Report No. 5/2006.

17. Vialard, J., G. Foltz, M. McPhaden, J-P. Duvel and C. de Boyer Montégut, 2008, Strong Indian Ocean sea surface temperature signals associated with the Madden-Julian Oscillation in late 2007 and early 2008, Geophys. Res. Lett., 35, L19608, doi:10.1029/2008GL035238.

18. Xie, S.-P., H. Annamalai, F.A. Schott, and J.P. McCreary (2002). Structure and mechanisms of South Indian Ocean climate variability, J. Climate, $15,864-878$.

19. Wainwright, L., G. Meyers, S. Wijffels, and L. Pigot, 2008: Change in the Indonesian Throughflow with the climatic shift of 1976/77, Geophys. Res. Lett., 35, doi:10.1029/2007GL031911.

20. Wijffels, S. E., J. Willis, C. M. Domingues, P. Barker, N. J. White, A. Gronell, K. Ridgway, and J. A. Church (2008). Changing Expendable Bathythermograph Fall Rates and Their Impact on Estimates of Thermosteric Sea Level Rise, $J$. Climate, 21, 5657-5672.
21. Potemra, J., 2005: Indonesian Throughflow transport variability estimated from Satellite Altimetry, Oceanography, 18, 99-107.

22. Sprintall J., S. Wijffels, T. Chereskin, and N. Bray, 2002: The JADE and WOCE I10/IR6 Throughflow sections in the southeast Indian Ocean. Part 2: velocity and transports, Deep Sea Res., Part II: Topical Studies in Oceanography, 49, 1363-1389.

23. Sakova, I, G. A. Meyers, R. Coleman, 2006: Interannual variability in the Indian Ocean using altimeter and IX1-expendable bathy-thermograph (XBT) data: Does the 18-month signal exist?, Geophys. Res. Let., 33 (20) 1-5.

24. Cai, W., H. Hendon, and G. Meyers (2005). Indian Ocean dipole-like variability in the CSIRO Mark 3 coupled climate model, J. Climate, 18, 1449-1468.

25. Qu, T. and G. Meyers (2004). Seasonal characteristics of circulation in the southeastern tropical Indian Ocean, J. Phys Oceanogr., 35, 255-267.

26. Feng, M., and G. Meyers (2003). Interannual variability in the tropical Indian Ocean: a two-year time-scale of Indian Ocean Dipole, Deep Sea Research Part II: Topical Studies in Oceanography, 50, 2263-2284.

27. Rao, S.A., V. V. Gopalkrishnan, S. R. Shetye, and T. Yamagata (2002b). Why were cool SST anomalies absent in the Bay of Bengal during the 1997 Indian Ocean dipole event?, Geophys. Res. Lett., 29, 1555, doi:10.1029/2001GL014645.

28. Meyers, G. 1996: Variation of Indonesian throughflow and the El Niño - Southern Oscillation, J. Geophys. Res., 101, 12,255-12,263.

29. Gopalakrishna, V.V., M.M. Ali, Nilesh Araligidad, Shrikant Shenoi, C.K. Shum and Yuchan Yi (2003). An atlas of XBT thermal structures and TOPEX/POSEIDON sea surface heights in the North Indian Ocean. NIO-NRSA-SP-01-03, NIO Special Publication.

30. Alory, G. and G. Meyers (2009). Warming of the Upper Equatorial Indian Ocean and Changes in the Heat Budget (1960-1999), J. Climate, 22, 93-113.

31. Du, Y., T. Qu, G. Meyers (2008). Interannual variability of the sea surface temperature off Java and Sumatra in a global GCM, J. Climate, 2451-2465.

32. Alory, G., S. Wijffels and G. Meyers (2007). Observed temperature trends in the Indian Ocean over 19601999 and associated mechanisms, Geophys. Res. Lett., 34, L02606, doi:10.1029/2006GL028044.

33. Wijffels, S. and G. Meyers, 2004: An intersection of oceanic waveguides - variability in the Indonesian throughflow region, J. Phys. Oceanogr., 34, 12321253.

34. Masumoto, Y. and G. Meyers, 1998: Forced Rossby Waves in the Southern Tropical Indian Ocean, $J$. Geophys. Res., 103, 27,589-27,602.

35. Cai, W., G. Shi, T. Cowan, D. Bi, and J. Ribbe (2005). The response of the Southern Annular Mode, the East Australian Current, and the southern mid-latitude ocean circulation to global warming, Geophy. Res. Let., 32, L23706, doi:10.1029/2005GL024701. 
36. McClean, J. L., D. P. Ivanova, and J. Sprintall , Remote origins of interannual variability in the Indonesian Throughflow region from data and a global POP simulation. Journal of Geophysical Research, 110, C10013, doi:10.1029/2004JC002477, 2005.

37. Schiller, A., 2004: Effects of explicit tidal forcing in an OGCM on the water-mass structure and circulation in the Indonesian throughflow region. Ocean Modelling, 6, 31-49.

38. Meyers, G., R. Bailey and T. Worby 1995: Volume transport of Indonesian throughflow, Deep Sea Res.I, 42, 1163-1174.

39. Rao, S. A., S. K. Behera, Y. Masumoto, and T. Yamagata (2002a). Interannual variability in the subsurface tropical Indian Ocean with a special emphasis on the Indian Ocean Dipole, Deep-Sea Res. II, 49, 1549-1572.

40. Luo, J.J., S. Masson, E. Roeckner, G. Madec, and T. Yamagata (2005). Reducing Climatology Bias in an Ocean-Atmosphere CGCM with Improved Coupling Physics, J. Climate, 18, 2344-2360.

41. Wijffels SE, Meyers G, Godfrey JS 2008: A Twenty Year Average of the Indonesian Throughflow: Regional Currents and the Inter-basin Exchange, $J$. Phys. Oceanogr., 38 (8), 1-14.

42. Masumoto, Y. \& Co-Authors (2010). "Observing Systems in the Indian Ocean" in these proceedings (Vol. 2), doi:10.5270/OceanObs09.cwp.60.

43. Roemmich, D., J. Gilson, B. Cornuelle and R. Weller (2001). The mean and time-varying meridional heat transport at the tropical/subtropical boundary of the North Pacific Ocean, J. Geophys. Res., 106, 89578970.

44. Roemmich, D., J. Gilson, J. Willis, P. Sutton, and K. Ridgway (2005). Closing the time-varying mass and heat budgets for large ocean areas: The Tasman Box, J. Climate, 18 (13), 2330-2343.

45. Garzoli, S., and M. O. Baringer (2007). Meridional heat transport determined with expandable bathythermographs - Part II: South Atlantic transport, Deep-Sea Res. part I, 54, 1402-1420.

46. Baringer, O. M., and S. L. Garzoli (2007). Meridional heat transport determined with Expendable Bathythermographs. Part I: Error estimates from model and hydrographic data. Deep-Sea Res. Part I, $54,1390-1401$.

47. Dong, S., S. Garzoli, M. Baringer, C. Meinen, and G. Goni (2009), Interannual variations in the Atlantic meridional overturning circulation and its relationship with the net northward heat transport in the South Atlantic, Geophys. Res. Lett., 36, L20606, doi:10.1029/2009GL039356.

48. Lentini, C., G. Goni and D. Olson (2006). Investigation of Brazil Current rings in the Confluence region, $J$. Geophys. Res., 111, doi:10.1029/2005JC002988, 2006.

49. Swart S., S. Speich, I. J. Ansorge, G. J. Goni, S. Gladyshev, J. R. E. Lutjeharms (2008).Transport and variability of the Antarctic Circumpolar Current south of Africa, J. Geophys. Res., 113, C09014, doi:10.1029/2007JC004223.

50. Morris, M, D. Roemmich and B. Cornuelle (1996) Observations of variability in the South Pacific Subtropical Gyre, J. Phys. Ocean., 26, 2359-2380.

51. Murty, V.S.N., M.S.S. Sarma, B.P. Lambata, V.V. Gopalakrishna, S.M. Pednekar, A. Suryachandra Rao, A.J. Luis, A.R. Kaka and L.V.G. Rao (2000). Seasonal variability of upper-layer geostrophic transport in the tropical Indian Ocean during 19921996 along TOGA-I XBT tracklines, Deep-Sea Research I, (47), 1569-1582.

52. Roemmich, D. and P. Sutton (1998). The mean and variability of ocean circulation past northern New Zealand: Determining the representativeness of hydrographic climatologies. Journal of Geophysical Research, 103, 13041-13054.

53. Gourdeau, L., W.S. Kessler, R.E. Davis, J. Sherman, C. Maes, and E. Kestenare (2008), Zonal jets entering the Coral Sea, J. Phys. Oceanogr., 38, 715-725.

54. Sutton, P., M. Bowen and D. Roemmich (2005). Decadal temperature changes in the Tasman Sea, New Zealand Journal of Marine and Freshwater Research, 39, 1321-1329.

55. Gilson, J, D. Roemmich, B. Cornuelle and L.-L. Fu (1998). Relationship of TOPEX/ Poseidon altimetric height to the steric height and circulation in the North Pacific, J. Geophys. Res., 103, 27947-27965.

56. McCarthy, M., L. Talley and D. Roemmich (2000) Seasonal to interannual variability from expendable bathythermograph and TOPEX/Poseidon altimetric data in the South Pacific subtropical gyre, $J$. Geophys. Res., 105, 19535-19550.

57. Goni, G. and M. Baringer (2002). Ocean Surface Currents in the Tropical Atlantic Across High Density Line AX08, Geophys. Res. Lett., 29(24), 2218, doi:10.1029/2002GL015873.

58. Gilson, J. and D. Roemmich (2002). Mean and temporal variability in Kuroshio geostrophic transport south of Taiwan (1993-2001). Journal of Oceanography, 58, 183-195.

59. Ridgway, K. and J.R. Dunn (2003). Mesoscale structure of the mean East Australian Current system and its relationship with topography. Progress in Oceanography, 56, 189-222.

60. Goni, G. and I. Wainer (2001). Investigation of the Brazil Current Front Dynamics from Altimeter Data, J. Geophys. Res., 36, 31,117-31,128.

61. Roemmich, D. and J. Gilson (2001). Eddy transport of heat and thermocline waters in the North Pacific: A key to interannual/decadal climate variability, $J$. Phys. Ocean., 31, 675-687.

62. Sutton, P. and D. Roemmich (2001). Ocean temperature climate off north-east New Zealand, New Zealand Journal of Marine and Freshwater Research, 35, 553-565.

63. Roemmich, D. and B. Cornuelle (1992) The subtropical mode waters of the South Pacific Ocean, J. Phys. Ocean., 22, 1178-1187. 
64. Tsubouchi, T., T. Suga and K. Hanawa (2007). Three types of South Pacific Subtropical Mode Waters: Their relation to the large-scale circulation of the South Pacific subtropical gyre and their temporal variability, J. Phys. Ocean., 37, 2478-2490.

65. Holbrook, N. and A. Maharaj (2008). Southwest Pacific Subtropical Mode Water: A climatology, Progress in Oceanography, 77, 298-315.

66. Green A. W. (1984). Bulk dynamics of the expendable bathythermograph (XBT), Deep-Sea Res., 31, 415483.

67. Hallock, Z. R., and W. J. Teague (1992). The fall rate of the T-7 XBT, J. Atmos. Oceanic Technol., 9, 470 483.

68. Fedorov, K. N., A. I. Ginzburg, and A. G. Zatsepen (1978). Systematic differences in isotherm depths derived from XBT and CTD data. POLYMODE News, 50(1), 6-7.

69. Flierl, G. and A. R. Robinson (1977). XBT measurements of the thermal gradient in the MODE eddy, J. Phys. Oceanogr., 7, 300-302.

70. McDowell, S., A note on XBT accuracy (1977). POLYMODE News, 29(1), 4-8.

71. Seaver, G. A., and S. Kuleshov, 1982: Experimental and analytical error of expendable bathythermograph, J. Phys. Oceanogr., 12, 592-600.

72. Singer, J. (1990). On the error observed in electronically digitized T7 XBT data. J. Atmos. Ocean. Tech., 7, 603-611.

73. Kizu, S., and K. Hanawa (2002). Start-up transient of XBT measurement by three types of Japanese recorder system, Deep-Sea Res., 49(5), 935-940.

74. Anderson, E.R. (1980). Expendable Bathythermograph (XBT) Accuracy Studies. NOSC Technical Report 550.Naval Ocean Systems Center, San Diego, California, pp 201.

75. Hanawa, K., P. Rual, R. Bailey, A. Sy, and M. Szabados (1995). A new depth-time equation for Sippican or TSK T-7, T-6 and T-4 expendable bathythermographs (XBT), Deep Sea Res. I, 42, 1423-1451.

76. Gouretski, V. V., and K. P. Koltermann (2007). How much is the ocean really warming? Geophys. Res. Lett., 34, L01610, doi:10.1029/2006GL027834.

77. Willis, J. K., J. M. Lyman, G. C. Johnson, J. Gilson (2008). In Situ Data Biases and Recent Ocean Heat Content Variability. J. Atmos. Ocean. Tech. 26, 4, 846-852. doi:10.1175/2008JTECHO608.1.
78. Kizu, S. S. Ito, T. Watanabe (2005). Intermanufacturer differences and temperature dependency of the fall rate of T-5 expendable bathythermograph, J. Oceanogr., 61, 905-912.

79. Kizu, S., O. Hiroji, T. Suga, K. Hanawa, T. Watanabe, H. Iwamiya (2008). Evaluation of the fall rates of the present and developmental XCTDs, Deep Sea Res., Part I, 55, 571-586.

80. Thadathil P., A. K. Saran, V.V. Gopalakrishna, P. Vethamony, and N. Araligidad (2002). XBT fall rate in waters of extreme temperature: A case study in the Antarctic Ocean, J. Atm. Ocean Tech., 19, 391-396.

81. DiNezio, P. N. and G. J. Goni, Identifying and estimating biases between XBT and Argo observations using satellite altimetry (2009), J. Atm. Ocean Tech., 27, 226-240, doi:10.1175/2009JTECHO711.1.

82. Wei, J., D.-P. Wang, and C.N. Flagg, 2008. Mapping Gulf Stream warm core rings from shipboard ADCP transects of the Oleander Project. J. Geophys. Res., 113, C10021, doi:10.1029/2007JC004694.

83. Rossby, T., C. Flagg, and K. Donohue (2005). Interannual variations in upper ocean transport by the Gulf Stream and adjacent waters between New Jersey and Bermuda, J. Mar. Research, 63, 203-226.

84. Goni, G. \& Co-Authors (2010). "The Ocean Observing System for Tropical Cyclone Intensification Forecasts and Studies" in these proceedings (Vol. 2), doi:10.5270/OceanObs09.cwp.36.

85. Goni G. J., M. DeMaria, J. Knaff, C. Sampson, I. Ginis, F. Bringas, A. Mavume, C. Lauer, I-I Lin, M. M. Ali, Paul Sandery, S. Ramos-Buarque, K. Kang, A. Mehra, E. Chassignet, and G. Halliwell (2009). Applications of satellite-derived ocean measurements to tropical cyclone intensity forecasting, Oceanography, 22, (3), 176-183.

86. Goni G. J. and J. Knaff (2009). Tropical Cyclone Heat Potential, In State of the Climate in 2008, 90, S54S56, Bull. Am. Met. Soc. 